\title{
Analysis of Juvenile Delinquency and Academic Attainment among Foster Care Youth in Kinship versus Non-Kinship Care
}

\author{
Donna F. Ossorio, PhD. \\ Assistant Professor \\ Delta State University \\ Cleveland, Mississippi 38733 \\ United States of America \\ Jackson de Carvalho, PhD \\ Associate Professor \\ Prairie View A \& M University \\ Prairie View, Texas 77446 \\ United States of America
}

\begin{abstract}
The U.S. Department of Health and Human Services (DHHS) has reported that over 500,000 foster care children were admitted to the foster care system for the fiscal year of 2015. The overall annual cost of foster care placement in the U.S. exceeds 9 billion dollars, a value shared by both the state and federal entities. The lack of effective placement and services often lead to low academic attainment and higher probability for the child to become adjudicated delinquent. The costs for negative foster care child outcomes include, emotional, physical, and psychological impairment, coupled with the separation of biological families, in many cases surpasses the monetary costs of foster care placement. Placement in foster care affects children's emotional development, which can lead to adverse outcomes on behavior and mental health due to inconsistent nurturing and lack of parental contact. Although placement in kinship care is the first option when parents are unavailable or cannot raise the child, non-kinship care is the most popular form of placement. Little is known to date as to whether the type of placement affects outcome measures of foster children such as delinquent behaviors and academic attainment. The current research study will compare the kinship and nonkinship foster care regarding placement stability and second, test the impact of removal reasons from their home as it pertains to delinquent behavior and educational attainment of children placed in foster care.
\end{abstract}

Keyword: Foster Care, Kinship, Non-Kinship, Outcomes, Academics Attainment

\subsection{Introduction}

The needs of kinship foster homes differ from those of non-kinship foster homes. While foster care relatives may know the child and have a good sense of the responsibility they are taking on, they may need more help in managing the complexities of family relationships. Many kinship caregivers are African-American women (Foster, Hillemeier, \& Bai, 2011). A number of studies show that kinship caregivers had received no formal training (Berrick, Barth, \& Needell, 1994); were less likely to be offered services than non relative caregivers, and received lower levels of monitoring (Berrick et al., 1994; Dworsky, Napolitano, \& Courtney, 2013; Testa, 2013) were less likely to be offered special needs services or special service needs increments in financial support (Berrick et al., 1994).In addition, poverty is an issue for kinship caregivers. Placements with relatives tend to be longer than those in traditional foster homes (Hegar\& Rosenthal, 2009). Courts routinely permit children to stay in relative foster care longer than federal timelines allow, as they are already with family (Hegar \& Scannapieco, 1999). A sense of family obligation and attachment to the children make the placements stable, but older caretakers can become exhausted (Hegar, \& Rosenthal, 2009). However, research indicates that the type of foster care setting (kinship or non-kinship) does not determine the length of stay in the system (Foster, Hillemeier, \& Bai, 2011; Vanschoonlandt, Vanderfaeillie, Holen, De Maeyer, \&Andries, 2012; Wu, White, \& Coleman, 2015).

Comparative foster care research often points to the demographic deficits of kinship care (Belanger, 2002). Paradoxically, children who experience kinship placement seem to fare better than children from non-kinship care. Children in kinship foster care tend to thrive better and have fewer emotional problems than those in non-kinship placements (Belanger, 2002; Berrick, Barth, \& Needell, 1994). Kin caregivers often provide a more supportive and stable relationship due to the personalized investment the caregiver has in the child, which may compensate for possible early abuse and trauma (Keller, Wetherbee, LeProhn, Payne, Sim, \& Lamont, 2001). 
Children in non-kinship foster care often experience more behavioral problems than those under the supervision of a kin foster parent (Belanger, 2002). Most of the behavioral problems are associated with aggressive behavior, antisocial behavior, somatic complaints, and attention deficit disorders.

Additionally, children in kinship placements show better levels of adaptive functioning and communication skills lending credence to the hypothesis that living with kin prevents the development of additional emotional problems. Additionally, it may help to improve the child's coping skills by offering a loving and supportive environment (Belanger, 2002; Keller, et al., 2001). Children who live in kinship foster care also have a decreased risk of maltreatment reports while in care as compared to children in non-kinship foster care. Despite these promising findings, very little is known about the long-term advantages of foster care alumni who spent time in kinship care compared to those who did not have kinship placements (Koh, 2010).

\subsection{Literature Review}

The relevant literature shows numerous studies comparing kinship and non-kinship care and how the type of placement effects outcome measures of foster children such as their academic status and their likelihood of engaging in delinquent behaviors (Koh, 2010). Many studies, however, have focused on behavioral challenges of children placed in foster homes (Fairneau, 2016). Moreover, there are varying results regarding determining which type of placement is more beneficial for foster children (Koh, 2010; Zinn, 2012). There is also a limited amount of literature addressing a decrease in legal permanency among kinship foster care placement as opposed to non-kinship foster care placement.

The review of the current literature points to a lacuna in empirical studies in the area of foster care as they relate to positive or negative outcomes of children in kinship versus non-kinship placements. Studies found in the relevant literature tend to have non-probability samples and lack comparison groups. Studies that have used comparison groups often are not generalizable due to the variations in the definition of kinship and non-kinship care and the benefits associated with such placements. For example, in the state of Texas, kinship care consists of blood or marriage relations, including fictive kin (not related by birth or marriage, but hold an emotional relationship). Many states do not consider fictive kin as kinship placement. Another gap revealed in the literature is that foster care research lacks comprehensive comparisons between kin and non-kin caregivers. Kin caregivers differ from non-kin caregivers in significant ways. This study contributed to the body of knowledge while aiming to narrow the research gap regarding outcome comparisons between kin and non-kin caregivers.

Furthermore, there is limited research comparing the prevalence of emotional and behavioral problems of youth in kinship and non-kinship care. Most studies conducted relied primarily on caregiver report of emotional and behavioral issues (Berrick, Barth, \& Needell, 1994; Rubin \& Babbie, 2016). Results from these studies indicated that youth in kinship care experience fewer emotional and behavioral problems than youth in non-kinship care. However, when researchers use teacher report and youth self-report, the results do not indicate that youth in kinship care experience fewer emotional and behavioral problems than youth in non-kinship care (McMillen, Zima, Scott, Auslander, Munson, \& Ollie, 2005; Shore, Sim, Prohn, \& Keller, 2002). Thus, the correlation between the type of placements and the emotional or behavioral outcome is still inconclusive.

\subsection{Types of Placement}

The main types of placement found in the literature are associated with kinship and non-kinship placements and childrelated attributes. Melkman, Refaeli, and Benbenishty (2016) defined kinship placement as: The full-time nurturing and protection of children who must be separated from their parents by relatives, step-parents or other adults who have a kinship bond with a child. This definition is designed to be inclusive and respectful of cultural values and ties of affection. It allows a child to grow into adulthood in a family environment(p. 2).

Most cultures value and maintain the practice of relatives caring for their children as a tradition (Bell \& Garner, 1996). The extended family has long played a role in caring for children whose parents were unable to do so; a practice commonly referred to as kinship care. Kinship foster care, also called relative foster care, is a relatively new adaptation of a long-used resource for children who cannot remain within their own homes, but whose extended families have the capacity to care for them (Courtney, Dworsky, Ruth, Havlicek, Perez, \& Keller,2007). Relatives have always taken in children who needed them, and this tradition continues. Of the approximately 2 million children in the care of grandparents, aunts, and uncles, and other relatives, only about 200,000 are living in formal kinship care foster homes, which are part of the child welfare system (Child Welfare Information Gateway, 2012a). A formal kinship care foster home is one in which the relative home meets foster care licensing standards, is under the supervision of the child welfare agency, and receives payments for the child's maintenance as a non-kin family would (Conway, \& Hutson, 2007). 
The use of relative's homes within the child welfare system has grown rapidly in recent years, with most of the growth in number of foster homes being kinship foster homes. Almost all states give preference to relatives when children need out of home care (Evans, 2014).

The demographic characteristics of kin caregivers include being older, single, having low income and being less educated than non-kinship adoptive parents (Evans, 2014). Recent statistics indicate that grandmothers and aunts usually cared for children placed under kinship foster homes. Kin foster mothers have an average age ranging from 50 to 60 -years-old, with $50 \%$ being grandmothers and $30 \%$ being aunts. Thirty percent of them had less than a high school education (Jenkins, 2002). Kin caregivers are more often single than non-kin foster mothers, who are typically married. Yet, the positive outcomes associated with affectional ties with kinship, particularly grandmothers, mitigate or outweigh the financial costs associated with caring for a child (Lenth, 2016). Minority families have a long history of caring for extended family members, particularly children when there is a loss or separation from parents. The extended family culture has been a source of resilience and emotional support through difficult experiences (Child Welfare Information Gateway, 2012a).

The Center for Disease Control and Prevention (Evans, 2014) rated kin caregivers in poorer health than non-kin foster parents. Such characteristic makes most kin caregivers living on a low-income budget. Having to support an additional member of the family, increases the financial stress of kin caregivers. Often kin caregivers experience economic challenges before the child's placement and are reluctant to apply for public benefits, which can be stigmatizing (Ehrle\& Green, 2002). Additionally, a gross disparity exists between the training and financial supports available to non-kin foster parents over kin caregivers (Hill, 2012). Title IV-E benefits afforded to non-kinship caregivers are not made accessible to relative caregivers as foster home licensure is not available (Denby, 2010).

The landmark decision of Miller v. Youakim (1979)has played a significant role in determining equity of federal foster care payments and services to kin who care for Title IV-E-eligible children and who may not meet the same state licensing standards as non-kin foster parents. Unfortunately, the court was silent on how states should fund non-IV-Eeligible children under kinship care. As a result, many states still deny foster care payments to kinship foster parents who care for children not eligible under Title IV-E. Although many court challenges have been raised arguing that such unequal treatment amounts to a constitutional violation of equal protection, payments services to children not eligible under Title IV-E continue to be denied in many statesEhrle\& Green, 2002.

\subsection{Method}

This section provides an overview of the methodology used in this study, which includes data collection, research hypotheses, study population, sampling, and operationalization of variables. A discussion of secondary data analysis of two datasets: Foster Care Analysis and Reporting System (AFCARS) and the National Youth Transition Database (NYTD) were presented. Finally, the internal and external validity were examined. Prior to compiling the data, permission was obtained from the Institutional Review Board (IRB) at Prairie View A\&M University. The data were de-identified by the agencies before giving access to the researcher.

The datasets were provided to the researcher by the Program Analytics and Evaluation Team at (NDACAN). The researcher entered into a formal agreement with (NDACAN), which permitted the use of the Adoption and Foster Care Analysis and Reporting System (AFCARS) and the National Youth in Transition Database (NYTD) to conduct academic and publishable research. Although the agencies compiled the data from all 50 states, the District of Columbia and Puerto Rico, the data for the present reflected only the state of Texas.

\subsection{AFCARS}

Under the supervision of the Health and Human Services Commission (HHSC), the AFCARS collects case-level information from state and tribal Title IV-E agencies on all children in foster care and those who have been adopted with Title IV-E agency involvement. Title IV-E agencies are required to report child-specific data through AFCARS twice a year. The AFCARS is a federally supported comprehensive case management tool, which houses official record of all states. The AFCARS data provided demographics, as well as measures of placement type, removal reasons, placement history, placement outcomes, and other information related to youth's ability to successfully transition from care (National Data Archive on Child Abuse and Neglect [NDACAN], 2016).

\subsection{NYTD}

NYTD dataset often consisted of two components, which were initiated by the John Chafee Foster Care Independence Program (CFCIP), in collaboration with the U.S. Department of Health and Human Services (DHHS) to collect two kinds of datasets to improve outcomes for youth in foster care. The first dataset consisted of information and services, which included the number and characteristics of children who received services, and the type and quality of services (NYTD user guide, 2016). 
The second outcome data included measures of educational attainment, high school diploma, employment, avoidance of dependency, homelessness, non-marital childbirth, incarceration, and high-risk behaviors (NYTD user guide, 2016).

\subsection{Study Population}

The study population comprised of all children who experienced kinship and non-kinship placement in the State of Texas. The children in the study were in legal placement in Texas between October 1, 2012, and November 1, 2015. Legal placement with a non-parent caregiver means a child was not reunified with a parent and had experienced nonkin adoption, kin adoption, or permanent managing conservatorship with kin or non-kin caregiver. In Texas, permanent managing conservatorship occurs when Child Protective Services (CPS) concludes that adoption with the child's relatives or other adults is not a feasible alternative. Then the court grants custody of the child to either an identified caregiver or to the Department of Family and Protective Services (The Texas Family Code Online, 2016). Permanent managing conservatorship is equivalent to what is referred to as guardianship in federal policy and the literature. Nevertheless, for this study, the term managing conservatorship was used since the focus was on children placed in foster homes in the State of Texas.

\subsection{Sampling}

The study used the AFCARS and the NYTD data to draw a systematic sample of 402 children to test the research hypotheses. The SPSS program divided the size of the Texas foster children population $(n=800)$ by the desired sample size $(n=402)$. Setting the alpha level at .05 , it was determined that a sample size of 160 would result in a power of .80 . Since the present study had a sample size of 402, it met and exceeded the recommend 160 sample size requirements calculated by the power analysis satisfying all proposed rule of thumb of the current research literature. Given that the present study had an adequate sample size with a confidence level set at .05 , the possibility of committing a Type I error was minimal. A Type I error happens when the null hypothesis is falsely rejected (Rubin \& Babbie, 2016). On the other hand, an adequate sample size with an alpha of .05 increases the effect size and reduces the probability of committing a Type II error, which is the failure to reject a false null hypothesis (Rubin \& Babbie, 2016; Rosenthal, 2012).

\subsection{Operationalization of Variables}

Based on the hypotheses established for this study, the following variables were operationalized. The independent variables for the study are placement type, academic support, post-secondary educational support, financial assistance, and demographic variables. The dependent variables were academic attainment, and adjudicated delinquent.

\subsection{Data Analysis}

Statistical Package for the Social Sciences (SPSS v. 24) was used to analyze the data. The data analysis was divided into two sections, descriptive and inferential statistics. Descriptive statistics included the frequencies and percent, which allowed for comparison of variables such as kin and non-kinship, as well as demographic variables of age, race/ethnicity, and gender, across the two groups of youth placed in kinship and non-kinship care. Inferential statistics (i.e., linear and logistic regressions) were employed to explain the effect of predictor variables (e.g., placement type, removal reasons, placement stability, and academic attainment) on adjudicated delinquent across the two groups of kinship and non-kinship care.

Linear statistical technique examines the relationship of independent and dependent variables across levels while controlling for a set of variables. Regression is a statistical technique that can disentangle the relationships among the variables. Regression analysis yields an equation that can be used to predict a dependent variable given one or more known variables. These equations can predict future values based on known information and the relationships between the variables (Vogt, 2005).

Hierarchical regression is a statistical method developed to better understand relationships within data aggregated at more than one level (i.e., beyond the individual-level), such as removal reasons and placement type (Luke, 2004). It is noteworthy that hierarchical regression approaches may be applied to a variety of analytic modeling techniques (including linear and binary logistic regression), offering the researchers considerable flexibility in their selection of variables and procedures to test a research hypothesis (Luke, 2004). For the purpose of this research, Hierarchical regression was used to test the first, second and third hypothesis allowing for the variables to be entered in two different steps generating Model A and Model B. As the current study investigated hypotheses with binary outcomes, assumptions made about the distribution (i.e., multicollinearity while the data had influences occurring at different levels) of the dependent variable across groups were violated, requiring an alternative multi-level modeling approach. Logistic regressions models provide a solution for multi-level data. 
This class of multi-level modeling technique accommodates binary logistic regressions as the outcome variable is dichotomous (Rosenthal, 2012). Therefore, this technique is appropriate to examine the second, and third hypotheses.

Chi-square statistical technique, which is part of the logistic regression analysis, was used to test the relationship between variables of all four hypotheses. Furthermore, to maximize reliability of the statistical analysis, the researcher followed the most cited statistical literature to test the underlying assumptions for the regression analysis, which include, a) normal distribution of continuous variables, b) no multicollinearity, c) linearity between independent and dependent variables, and d) homoscedasticity and reliability of all variables. Any statistical indices that may have violated regression assumptions were addressed to the extent possible Rosenthal, 2012).

After assessing whether assumptions of the data were met, multi-level logistic regression techniques were employed, sequentially introducing variables in a hierarchical fashion, within two separates, but parallel, modeling procedures assessing the effect of the first set of predictors, sexual abuse, physical abuse, and neglect and the second set of variables of placement type on the dependent variable, adjudicated delinquent.

\subsection{Hypotheses}

The study aimed to test a set of research hypotheses originated from an extensive review of the relevant literature. Using a quantitative research approach, this study addressed the following research hypotheses:

H1: When controlling for age and race/ethnicity of the child, placement type are significant predictors of placement stability.

H2: Placement type, removal reasons, academic attainment, and high school graduation are related to a higher likelihood of adjudicated delinquent when controlling for age, race/ethnicity, and gender.

H3: Youth's lower level of academic attainment will have a higher likelihood of becoming adjudicated delinquent, compared to youth who did have a higher level of academic attainment, and this relationship is stronger for youth in non-kinship care compared to kinship care.

Hypothesis 1.To answer the first research hypothesis (When controlling for age, race and sex of the child and placement type are significant predictors of placement stability) used a hierarchical linear regression model to determine the influence of Sex (males=0, females=1) and Placement Type (kinship placement $=1$, non-kinship placement $=0$ ) on Placement Stability while controlling for age and race. The first set of variables, age, and race were entered were entered as control variables to create the first model, Model A, and the other variables, Sex of the child and Placement Type were subsequently introduced to create the second model, Model B. Hierarchical analyses were conducted using a normalized Placement Stability as the dependent variable. The Hierarchical regression technique was used to examine the ability of the model to predict placement stability among foster care children. These multivariate analyses examined the independent variables individually and in combination to determine the proportion of variance that each variable explained.

Hierarchical linear regression compared each of the variables measuring the difference between the child's age, sex, race, and type of placement between of the children in the study. The significance level was set at .05. The regression analysis allowed determining whether females in kinship care had lower levels of placement stability compared to males as proposed by the first hypothesis Rosenthal, 2012).

Hypothesis 2. The second research hypothesis (Placement Type, Removal reasons, Academic Attainment, and High School Grad are associated to a higher likelihood of adjudicated delinquent when controlling for race, age, and sex) was tested using a hierarchical binary logistic regression to examine the effect of four predictor variables on Adjudicated Delinquent. The first model, Model A was generated by entering the first set of control variables (race, age, and sex). The variables, Placement Type, Removal Reasons, Academic Attainment and High School Grad, were entered in the second model, Model B. The variables were entered in a hierarchical manner, which was guided by the research on a foster children Placement Type, Removal Reasons, Academic Attainment and High School Grade on Adjudicated Delinquent data. This was done to explore the variables relationship and explanatory power while making sure each had a distinct contribution to the regression model.

Hypothesis 3. The third research hypothesis (Youth lower level of academic attainment will have a higher likelihood of becoming adjudicated delinquent, compared to youth who did have a higher level of educational attainment, and this relationship is stronger for youth in non-kinship care compared to kinship care) was addressed using a binary logistic regression.

Logistic regression was used to explain the relationship between multiple independent indicator variables defining the latent variable, Academic Attainment entered simultaneously to predict membership of one the group membership of the dependent variable, Adjudicated Delinquent. 
Pseudo-R-squared statistics were examined to evaluate model significance, where increases in the pseudo R squared statistic represented additional variability explained within models (Freese \& Long, 2006). Additionally, likelihood ratio tests were employed to compare the relative significance of the model as blocks of predictors were added. Additionally, increases in the pseudo-R-squared statistic represented additional variability explained within the model (Freese \& Long, 2006; Rosenthal, 2012).

\subsection{Results}

\subsection{Demographic characteristics.}

One-third of the youth $(\mathrm{n}=143,35.6 \%)$ were 16 years-of-age, followed by 15 years-of-age $(\mathrm{n}=118,29.4 \%)$. The least represented population was the 14 years old youth $(\mathrm{n}=66,16.4 \%)$, followed by the 17 -years-old $(\mathrm{n}=56,13.9 \%)$. Those who are older than $17(\mathrm{n}=19,4.6 \%)$ represented less than 5\% (see Table 1). Regarding race/ethnicity of the youth, slightly less than one-third $(\mathrm{n}=153,31.1 \%)$ were Hispanic, followed by almost one-third $(\mathrm{n}=117,29.1 \%)$ White, and a quarter $(\mathrm{n}=103,25.6 \%)$ African American. Comparatively, 50\% of the Texas youth population is Hispanic, 32\% are White, and approximately 11\% are African American (DFPS, 2015). Other ethnicities accounted for $7.2 \%(\mathrm{n}=29)$ of the sample. The race/ethnicity of the sample shows that African American youth were disproportionately represented. Males represented over 50\% $(\mathrm{n}=221,55 \%)$ of the sample, compared to females $(\mathrm{n}=$ 181, 45\%; see Table 1).

Table 1. Frequency Distribution of Age, Race/Ethnicity and Gender of Youth

\begin{tabular}{|c|c|c|c|}
\hline $\begin{array}{c}\text { Demographic } \\
\text { Variables } \\
\end{array}$ & Frequency & Percent & $\begin{array}{c}\text { Cumulative } \\
\text { Percent }\end{array}$ \\
\hline 13 & 8 & 2.0 & 2.0 \\
\hline 14 & 66 & 16.4 & 18.4 \\
\hline 15 & 118 & 29.4 & 47.8 \\
\hline 16 & 143 & 35.6 & 83.3 \\
\hline 17 & 56 & 13.9 & 97.3 \\
\hline 18 & 7 & 1.7 & 99.0 \\
\hline 19 & 3 & .7 & 99.8 \\
\hline 20 & 1 & .2 & 100.0 \\
\hline Total & 402 & 100.0 & \\
\hline \multicolumn{4}{|l|}{ Race/Ethnicity } \\
\hline White & 117 & 29.1 & 29.1 \\
\hline African American & 103 & 25.6 & 54.7 \\
\hline Hispanic Origin & 153 & 38.1 & 92.8 \\
\hline Other & 29 & 7.2 & 100.0 \\
\hline Total & 402 & 100.0 & \\
\hline \multicolumn{4}{|l|}{ Gender of Youth } \\
\hline Male & 221 & 55.0 & 55.0 \\
\hline Female & 181 & 45.0 & 100.0 \\
\hline Total & 402 & 100.0 & \\
\hline
\end{tabular}

\subsection{Inferential Data Analysis}

The inferential data analysis for this research study involves testing a set of research questions, which will include the application of Hierarchical Linear Modeling: A statistical technique that examines the relationship of independent and dependent variables across nested levels while controlling for a set of variables. Hierarchical or multiple regression are statistical techniques that can disentangle the relationships among the variables in a non-equivalent research group design. Regression analysis yields an equation that can be used to predict a dependent variable given one or more known variables. These equations can forecast future values based on known information and the relationships between the variables (Vogt, 2005). The method will also indicate the relative degree that each independent variable contributes to the dependent variable.

For prediction purposes, no other statistical technique is as flexible, efficient and precise as regression analysis because it can predict a single dependent outcome variable from one or more independent predictor variables. The predictor variables can be continuous variables or can be a dummy or dichotomous variable, having values of zero or one indicating group membership. The regression analysis will also yield a multiple correlation. 
The square of the multiple correlation determines the proportion of the variance that the independent variables contribute to predicting the dependent variable in a regression analysis.

Hierarchical regression modeling has several advantages over multiple regression. Hierarchical regression accounts for group membership, it does not violate the independence of observation assumption of regression. Hierarchical modeling was developed to disentangle the influence of multilevel data such as controlled variables, individual or institutional level. Hierarchical regression modeling assigns the appropriate degrees of freedom to nested data. At the same time, Hierarchical regression modeling can detect the value-added effects of predictors on the dependent variable after controlling for contextual variables.

As with other statistical methods, multiple regression makes certain assumptions regarding the data set. According to Rosenthal (2012), these assumptions include: each of the variables is normally distributed; the predictor variables are measured without error; the deviations, residuals or errors have an expected value of zero and are independently and normally distributed; and for a specified predictor variable, the values of each case are independent. One of the problems associated with regression analysis is that of multicollinearity, a condition where there are strong correlations among the independent variables (Vogt, 2005). Multicollinearity can be detected when the variance inflation factor (the reciprocal of the difference of one and the $\mathrm{r}$ square) is large. Although there is no agreement and no theoretical value to indicate what is large, Rubin and Babbie (2016) reported that a value larger than 7 is of some concern.

When multicollinearity occurs, the regression equation could be limited to prediction and adjust the interpretation of the model accordingly. In fact, Tabachnick and Fidell (2007) reported that the most convenient way to avoid the problem of multicollinearity is to use group mean or grand mean centered variables, because school means, and the difference of individual and school means are not correlated, and thus the assumptions of regression are not violated. Prior to conducting statistical tests, it is important to consider whether the data analyzed follows the assumptions of normality.

Most of the data was not normally distributed as results showed that $p \leq 0.05$ level of significance and the H0 should be rejected indicating the observed distribution does not fit the normal distribution, which was confirmed by the Shapiro Wilks test. Thus, appropriate remedial actions were made to transform the non-normal continuous data into a normalized data by using the log 10 command in SPSS. Although the transformed data still showed a $\mathrm{p} \leq 0.05$, and a skewness and kurtosis above -2 and +2 and larger than the standard error, the Normal Q-Q Plot indicated an improved approximation to normality. The researcher followed the guidance of the most frequently cited assumptions in the statistical literature, and any numerical indices that violated assumptions were transformed to meet statistical analysis guidelines.

\subsection{Hypothesis 1}

The first hypothesis (The sex of the child and placement type are significant predictors of placement stability when controlling for age and race) used a simple case of a hierarchical linear regression model to determine the influence of Sex and Placement Type (kinship=0, non-kinship=1) on Placement Stability while controlling for age and race. The variable Sex (sex of the child) was processed as a binary variable $(0=$ male, $1=f e m a l e)$. Placement Stability was processed as an interval/ratio composite variable defined by total days stay in fc, all episodes / total number of removals and normalized using a two steps transformation to normality in SPSS. The variable Placement Type was recoded and processed as a two-level variable ( $0=$ non-kinship, $1=$ kinship). The old category $2=$ Foster home, relative, was changed to $1=$ kinship placement and ELSE, was changed to $0=$ non-kinship placement. The variable age was processed as the age of the child on the first day of the fiscal year. The variable Race desegregated and processed as a dichotomous measure for each individual race of the foster child.

The first set of variables, age and race were entered as control variables to create the first block, block 1 . The other variables, Sex of the child and Placement Type were subsequently entered to create block 2 . Hierarchical analyses were conducted using a normalized dependent variable, Placement Stability. It is noteworthy that the test of assumptions showed that all correlations between predictors were not above .7, indicating no multicollinearity between the predictors. Nevertheless, correlations between the predictors and the outcome variable were below .3, indicating a weak correlation and low explanatory power of the model.

A hierarchical analysis was conducted using a block method with the control variables reflecting the individual characteristics of the child (age and race of the child characteristics). The results are displayed in Table 2. The overall model accounted for \% ( R2 =.090) of variance in placement stability. In block 1, the control variables, age and race characteristics contributed to $5.3 \%$ of the variance in placement satisfaction $(\Delta \mathrm{R} 2=.053)$. The variable, age of the child; was the only significant predictor in block 1 , with a small impact on placement satisfaction $(\beta=.029)$. 
In the overall model, this variable, age of the child continues to be a significant predictor with a very small influence on placement stability.

The variables, Placement Type and Sex of the child, block 2, were the only variables to have statistical significance in block 2. Sex of the child appears to be the least predictive of placement stability explaining $-6.7 \%$ of variance in placement stability $(\Delta \mathrm{R} 2=-.067)$. The variable, Placement Type, however, had the highest structure coefficient in block 2. Nevertheless, the effect of Placement Type on the placement stability of foster care children was still small as it explained $6.8 \%$ variance of placement stability $(\Delta \mathrm{R} 2=-.068)$.

\section{Table 2: Model SummaryQ23}

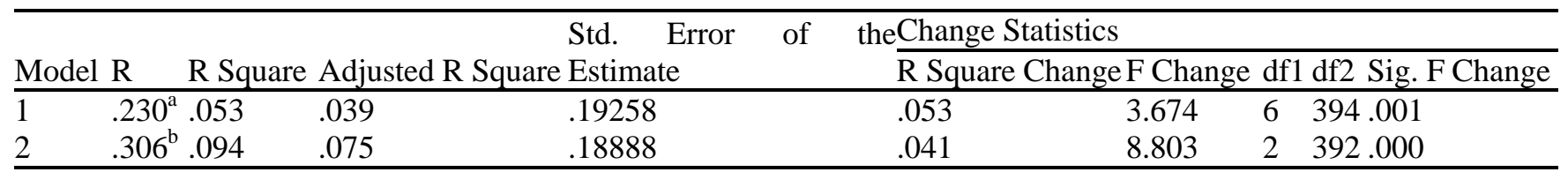

a. Predictors: (Constant), Hispanic, Amer Indian Native, Age, Asian, White, Black/African Amer

b. Predictors: (Constant), Hispanic, Amer Indian/Native, Age, Asian, White, Black/African Amer, Placement Type, Child Sex

c. Dependent Variable: NORM Sum: Total days stay in FC, all episodes STABILITY / Total Number of Removals (Stability 1 (RATIO).

As displayed in Table 3, three of the seven variables were statistically significant: Age ( $p=.003)$, Child Sex $(p=.004)$ and Placement Type $(p=.014)$. The strongest contributor to placement stability was the child's Placement Type $(\beta=$ .068). Although Age, Sex of the child and Placement Type had a small effect on the outcome variable, both variables were statistically significant, which substantiated the first hypothesis (When controlling for age and race, sex of the child and placement type are significant predictors of placement stability). Subsequently, the null hypothesis was rejected, and the alternative was accepted.

Table 3: Coefficients ${ }^{\mathrm{a}}$

\begin{tabular}{|c|c|c|c|c|c|c|c|c|c|c|c|}
\hline \multirow[b]{2}{*}{ Model } & \multicolumn{6}{|c|}{ Unstandardized CoefficientsStandardized Coefficients } & \multicolumn{2}{|c|}{ Correlations } & \multicolumn{3}{|c|}{ Collinearity Statistics } \\
\hline & $\mathrm{B}$ & Std. Error & \multicolumn{2}{|c|}{ Beta } & & $\mathrm{t}$ & \multicolumn{4}{|c|}{ Sig. Zero-orderPartialPartTolerance } & \multirow[t]{2}{*}{ VIF } \\
\hline 1 (Cons & .092 & .145 & & & & 635 . & .526 & & & & \\
\hline \multicolumn{2}{|l|}{ Age } & .027 & .009 & .152 & 3.060 & .002 & .177 & .152 & .150 & .969 & 1.032 \\
\hline \multicolumn{2}{|c|}{ Amer Native } & .119 & .193 & .030 & .614 & .539 & .029 & .031 & .030 & .995 & 1.005 \\
\hline \multicolumn{2}{|c|}{ Asian } & .121 & .137 & .043 & .881 & .379 & .036 & .044 & .043 & .992 & 1.008 \\
\hline \multicolumn{2}{|c|}{ African Amer } & .030 & .039 & .073 & .772 & .441 & .157 & .039 & .038 & .272 & 3.681 \\
\hline \multicolumn{2}{|c|}{ White } & -.034 & .040 & -.077 & -.855 & .393 & -.160 & -.043 & -.042 & .300 & 3.337 \\
\hline \multicolumn{2}{|c|}{ Hispanic } & -.001 & .023 & .-001 & -.024 & .981 & .080 & -.001 & -.001 & .727 & 1.376 \\
\hline \multicolumn{2}{|c|}{$\overline{2 \text { (Constant) }}$} & .128 & .146 & & .879 & .380 & & & & & \\
\hline \multicolumn{2}{|c|}{ Age } & .028 & .009 & .160 & 3.271 & .001 & .177 & .163 & .157 & .967 & 1.034 \\
\hline \multicolumn{2}{|c|}{ Amer Native } & .126 & .191 & .032 & .661 & .509 & .029 & .033 & .032 & .985 & 1.016 \\
\hline \multicolumn{2}{|c|}{ Asian } & .147 & .135 & .053 & 1.091 & .276 & .036 & .055 & .052 & .985 & 1.015 \\
\hline \multicolumn{2}{|c|}{ African Amer } & .041 & .038 & .098 & 1.057 & .291 & .157 & .053 & .051 & .270 & 3.699 \\
\hline \multicolumn{2}{|c|}{ White } & -.029 & .039 & -.065 & -.741 & .459 & -.160 & -.037 & -.036 & .299 & 3.340 \\
\hline \multicolumn{2}{|c|}{ Hispanic } & -.005 & .023 & -.013 & -.237 & .813 & .080 & .012 & .011 & .725 & 1.380 \\
\hline \multicolumn{2}{|c|}{ Child Sex } & -.070 & .019 & -.177 & -3.658 & .000 & -.157 & -.182 & -.176 & .982 & 1.018 \\
\hline \multicolumn{2}{|c|}{ Placement Type } & .068 & .023 & .109 & 2.243 & .025 & .091 & .113 & .108 & .986 & 1.015 \\
\hline
\end{tabular}

a. Dependent Variable: Norm Sum: Total days stay in FC, all episodes Stability / Total Number of Removals (Stability 1 (RATIO)

\subsection{Hypothesis 2}

To test the second hypothesis (Placement Type, Removal Reasons, Placement Stability, Academic Attainment and High School Grad are associated to a higher likelihood of adjudicated delinquent when controlling for race, age and sex) a hierarchical binary logistic regression was performed. 
Logistic regressions, by design, overcome many of the restrictive assumptions of linear regressions. For example, linearity, normality, and equal variances are not assumed, nor is it assumed that the error term variance is normally distributed. The major assumption is regarding the outcome variable, which must be discrete (Tabachnick\&Fidell, 2007).

The variables explored in the study were assessed for multicollinearity to ensure that each made a distinct contribution to the model. In logistic regression models, multicollinearity is the result of strong correlations between independent variables. The existence of multicollinearity inflates the variances of the parameter estimates. That may result, particularly for small and moderate sample sizes, in lack of statistical significance of individual independent variables while the overall model may be strongly significant. Furthermore, multicollinearity may result in wrong signs and magnitudes of regression coefficient estimates, and consequently it may also result in incorrect conclusions about relationships between independent and dependent variables (Tabachnick\&Fidell, 2007).

To assess for multicollinearity among the predictor variables, chi-square tests for independence were conducted to evaluate for interdependencies. The chi-square test for independence is a test of whether two categorical variables are associated with each other. After all the chi-squares were run, it was found that all the predictor variables had some degree of relationship, which indicated multicollinearity. However, Cramer's $\mathrm{V}$ was then calculated for each of the chisquare for independence analyses. Cramer's $\mathrm{V}$ is used to describe the magnitude of the association between categorical variables when the number of rows, columns, or both is greater than two.

Cramer's V must lie between 0 (reflecting complete independence) and 1.0 (indicating complete dependence or association) between the variables (Rosenthal, 2012). Conventions for describing the magnitude of association for Cramer's V are as follows: .00 and under .10 (negligible association), .10 and under .20 (weak association), .20 and under .40 (moderate association), and under .60 (relatively strong association), .60 and under .80 (strong association), and .80 to 1.00 (very strong association) (Rosenthal, 2012). Based on the chi-square for independence tests, the following variables were found to have a statistically significant relationship:

- How Physical Abuse influenced Adjudicated Delinquent $(\chi 2(1)=2.285 \mathrm{p}=.131$, Cramer's V=.075).

- How Sexual Abuse influenced Adjudicated Delinquent $(\chi 2(1)=7.113 \mathrm{p}=.008$, Cramer's V=.133).

- How Neglect influenced Adjudicated Delinquent $(\chi 2(1)=2.300 \mathrm{p}=.129$, Cramer's V=.076).

- How Placement Type influenced Adjudicated Delinquent $(\chi 2(1)=1.98 \mathrm{p}=.656$, Cramer's V=.022).

- How Age influenced Adjudicated Delinquent $(\chi 2(1)=7.579 \mathrm{p}=.371$, Cramer's V=.137).

- How Sex of the child influenced Adjudicated Delinquent $(\chi 2(1)=6.836 p=.009$, Cramer's V=079).

- How High School Grad influenced Adjudicated Delinquent $(\chi 2(1)=2.527 \mathrm{p}=.283$, Cramer's V=.079)

- How Academic Attainment influenced Adjudicated Delinquent $(\chi 2(1)=31.181 \mathrm{p}=.000$, Cramer's V=.279)

- How Placement Stability influenced Adjudicated Delinquent $(\chi 2(1)=389.317 \mathrm{p}=.008$, Cramer's V=.985).

These findings indicated that many of the predictor variables were not independent of one another. As such, their associations with one another could cause complications in regression analyses. The p-value was significant for four of the nine variables, the Cramer's V values contain five "negligible" associations (High School Grad, Sex of the child, Physical Abuse, Neglect and Placement Type) three weak associations (Age, Sexual Abuse, and Academic Attainment) and one very strong association (Placement Stability). Although specific variables could have been dropped from the model altogether, it was decided that there was enough uniqueness between the variables that they were left in the model.

Hierarchical entry of the variables into the model was selected as the appropriate means to deal with the control variables (Gender, Age, \& Race). In this method, the predictors are entered into the model progressively according to a theoretical order based on existing research and theory. Entry in this manner allowed the researcher to examine the unique contribution of each additional predictor to the variability of the dependent measure after controlling for the influence of the preceding predictors already in the model.

Hierarchical binary logistic regression examined the impact of the four predictor variables on Adjudicated Delinquent (yes vs. no). The predictor variables were entered into the model two times: The control variables Gender, Age and Race were entered in the first model, model A. Physical Abuse, Sexual Abuse, Neglect, High School Grad, Placement Stability and Placement Type were entered in the second model, model B; The variable Race was disentangled and processed as a dichotomous measure for each individual race of the foster child.

The first stage of the hierarchical binary logistic regression, model A was statistically significant, $\chi 2(3)=10.873, \mathrm{p}=$ .012 , suggesting that the overall model with the control variables, Gender, Age and Race did predict juvenile delinquency. 
It is important to consider that predicted probabilities were for membership for the category "Yes" of the outcome variable, Adjudicated Delinquent. Model A including only the control variables, accounted for (Nagelkerke R2) $17.3 \%$ of the variance in the outcome variable, Adjudicated Juvenile. See Table 4.

Table 4: Model Summary

\begin{tabular}{llll}
\hline Step & -2 Log likelihood & Cox \& Snell R Square & Nagelkerke R Square \\
\hline 1 & $188.050^{\mathrm{a}}$ & .073 & .173 \\
\hline
\end{tabular}

a. Estimation terminated at iteration number 20 because maximum iterations has been reached. Final solution cannot be found.

Model A, indicated that the variables, sex of the child and Hispanic Race of the child were statistically significant at $\mathrm{p}=$ .05 level of significance. It is noteworthy that the predicted probability is for membership for yes. Results indicated that the variable Sex of the child and Hispanic origin was the only statistically significant predictors for Model A. The variable Sex of the child yielded a B of 1.186 , S.E. $=.452$, Wald $=6.893, \mathrm{P}<.009$. Statistical indices indicated that one unit increase in this variable, Sex is associated with 1.186 increase in the logit of Adjudicated Delinquent. The $\operatorname{Exp}(B)$ was 3.274, which implies that the model predicts that the odds of the child becoming adjudicated delinquent is 3.274 times higher when the Sex of the child increased by one level. All else equal, a one-level increase in Sex (Sex or gender of the child) increased his or her chances of becoming adjudicated delinquent by $76.6 \%(100 *[3.274+1]=76.6 \%)$. Statistical indices indicated that this variable, Sex of the child, is a strong contributor to the model at $\mathrm{p}<.000$ level of significance.

For the variable, Hispanic (Hispanic race or ethnicity of the child) the b was 1.548, SE $=.509$, Wald $=9.229, \mathrm{P}<002$. and the $\operatorname{Exp}(\mathrm{B})$ was 4.701. Statistical indices indicated this variable, Hispanc (Hispanic race or ethnicity of the child) had a statistically significant effect $(B=1.548, \mathrm{p}<.002)$ on Adjudicated Delinquent. When the Hispanic race or ethnicity of the child increased by one unit, there was 1.548 of increase in the logit of the variable Adjudicated Delinquent. All else equal, a one-level increase in Hispanic (Hispanic race or ethnicity of the child) increased his or her chances of becoming adjudicated delinquent by $82.5 \%(100 *[4.701+1]=82.5 \%)$. Statistical indices indicated that this variable, Hispanic origin, is a strong contributor to the model at $p<.000$ level of significance. See Table 5.

Table 5: Variables in the Equation

\begin{tabular}{llllllllll}
\hline & & & & & & & \multicolumn{2}{c}{ 95\% C.I.for EXP(B) } \\
\cline { 3 - 8 } & & B & S.E. & Wald & df & Sig. & Exp(B) & Lower & Upper \\
\hline & Sex & 1.186 & .452 & 6.893 & 1 & .009 & 3.274 & 1.351 & 7.937 \\
& Amiakn & 19.820 & 40192.801 & .000 & 1 & 1.000 & 405392569.604 & .000 &. \\
Asian & 18.674 & 28417.699 & .000 & 1 & .999 & 128890377.157 & .000 &. \\
Blkafram & .069 & 1.111 & .004 & 1 & .951 & 1.071 & .121 & 9.455 \\
White & .060 & 1.147 & .003 & 1 & .958 & 1.062 & .112 & 10.054 \\
Hispanic & 1.548 & .509 & 9.229 & 1 & .002 & 4.701 & 1.732 & 12.760 \\
Age & -.079 & .176 & .202 & 1 & .653 & .924 & .654 & 1.304 \\
Constant & -41.414 & 49224.142 & .000 & 1 & .999 & .000 & & \\
\hline
\end{tabular}

A. Variable(S) Entered on Step 1: Sex, Amiakn, Asian, Blkafram, White, Hispanic, Age

The second stage of the hierarchical binary logistic regression, model B was statistically significant, $\chi 2(15)=46.346$, $\mathrm{p}=<000$, which suggested that by adding the variables the additional variables (Placement_Type, Phyabuse, Sexabuse, Neglect, Acad_Level, Financial_Assistance, Post_Secedu_Support,General_Acadasupport, Highschool_Grad, Number_Psetting,Length_Lastremoval, Length_Current_Psetting, Length_Previoussetting,

Total_Stay_Infc,Number_Removals) to the existing overall model did make a significant contribution to the model. The explanatory power of Model B reflected by the Nagelkerke R2, was 38.3\%.This indicated an addition of $55.6 \%$ of the variance on the outcome variable, Adjudicated Delinquent could be attributed to the inclusion of the additional variables. (see Table 6).

Table 6:Model Summary

\begin{tabular}{llll}
\hline Step & $-2 \log$ likelihood & Cox \& Snell R Square & Nagelkerke R Square \\
\hline 1 & $147.952^{\mathrm{a}}$ & .161 & .383 \\
\hline
\end{tabular}

a. Estimation terminated at iteration number 20 because maximum iterations has been reached. Final solution cannot be found. 
Table 6:Model Summary

\begin{tabular}{llll}
\hline Step & -2 Log likelihood & Cox \& Snell R Square & Nagelkerke R Square \\
\hline 1 & $147.952^{\mathrm{a}}$ & .161 & .383 \\
\hline
\end{tabular}

The Variable, Sex of the child remained statistically significant, but the variable Hispanic origin of the child was not statistically significant in the second model, Model B. Additionally, the variables, Financial_Assistance (financial assistance), Post_Secedu_Support (post-secondary education support), Length_Current_Psetting (length of days in current placement setting) were statistically significant at $\mathrm{p}=.05$ level of significance. The variable Financial_Assistance was measured at the nominal level and was found to be statistically significant with a negative effect on Adjudicated Delinquent ( $\mathrm{B}=-.2 .862, \mathrm{p}=.004)$, which indicated that one-level increase in this variable is associated with 2.862 decrease in the logit of Adjudicated Delinquent. The $\operatorname{Exp}(B)$ was .067 , indicating that when controlling for all other variable in the model, a one-level increase in Financial_ Assistance decreased his or her chances of becoming adjudicated delinquent by $40.1 \%(100 *[.067+1]=40.1 \%)$. Statistical indices indicated that this variable, financial assistance of the child, is a strong contributor to the model at $p<.000$ level of significance.

The variable Post_Secedu_Support (Post-Secondary Educational Support) was statistically significant and had a negative effect on the probability for the youth becoming adjudicated delinquent $(B=-1.425 \mathrm{p}<.016)$. Statistical indices indicated that a one-level increase in this variable Post_Secedu_Support, is associated with 1.425 decrease in the logit of Adjudicated Delinquent. In other words, for each unit of increase in the predictor of Post_Secedu_Support, there is a 1.425 times greater likelihood for the child not to become Adjudicated Delinquent. The variable, Post_Secedu_Support had an $\operatorname{Exp}(B)$ of .241. When controlling for the effects of the other involvement items, each level increase in the juveniles' the presence of services for post-secondary education decreased the odds of the child becoming adjudicated delinquent by $70.6 \%(100 *[.241+1]=70.6 \%)$. Taken together, these results suggest that engagement in post-secondary education was a statistically significant predictor of juvenile delinquency at $p<.000$ level of significance.

The last variable to be statistically significant predictor was Length_Current_Psetting (Length (days) in Current Placement Setting), which had a negative effect on the outcome variable, Adjudicated Delinquent $(\mathrm{B}=--1.582 \mathrm{p}<$ .006). When the length in current placement setting increased by one unit, there was 1.582 of decrease in the logit of lower level of Adjudicated Delinquent. The Exponential B for the variable, Length_Current_Psetting was .205. When controlling for all the other variables in the model, a one-level increase in the length of days the child had in current placement setting decreased the chances of she or he is becoming adjudicated delinquent by $67.2 \%(100 *[.205+1]$ $=67.2 \%)$. Statistical indices indicated that this variable, Length_Current_Pset, is a strong contributor to the model at $\mathrm{p}<$ .000 level of significance (See Table 7). 
Table 7: Variables in the Equation

\begin{tabular}{|c|c|c|c|c|c|c|c|c|c|}
\hline & & & & & & & & $\begin{array}{l}95 \% \\
\text { EXP(B }\end{array}$ & C.I.for \\
\hline & & $\mathrm{B}$ & S.E. & Wald & df & Sig. & $\operatorname{Exp}(B)$ & Lower & Upper \\
\hline$\overline{\text { Step } 1^{a}}$ & Sex & 1.156 & .580 & 3.968 & 1 & .046 & 3.178 & 1.019 & 9.911 \\
\hline & Amiakn & 19.463 & 40193.077 & .000 & 1 & 1.000 & 283691847.333 & 3.000 & . \\
\hline & Asian( & 18.023 & 27031.868 & .000 & 1 & .999 & 67165727.381 & .000 & . \\
\hline & Blkafram & 1.965 & 1.364 & 2.076 & 1 & .150 & 7.135 & .493 & 103.346 \\
\hline & White & 1.357 & 1.332 & 1.037 & 1 & .308 & 3.883 & .285 & 52.832 \\
\hline & Hispanic & .827 & .622 & 1.764 & 1 & .184 & 2.286 & .675 & 7.743 \\
\hline & Age & .195 & .232 & .704 & 1 & .401 & 1.215 & .771 & 1.914 \\
\hline & Placement_Type & -1.104 & .673 & 2.690 & 1 & .101 & .332 & .089 & 1.240 \\
\hline & Phyabuse & .622 & .520 & 1.431 & 1 & .232 & 1.862 & .672 & 5.159 \\
\hline & Sexabuse & 1.091 & .709 & 2.367 & 1 & .124 & 2.978 & .742 & 11.961 \\
\hline & Neglect & 1.323 & .774 & 2.924 & 1 & .087 & 3.754 & .824 & 17.103 \\
\hline & Acad_Level & 16.796 & 19671.689 & .000 & 1 & .999 & 19695203.319 & .000 & 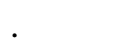 \\
\hline & Financial_Assistance & -2.709 & .942 & 8.263 & 1 & .004 & .067 & .011 & .422 \\
\hline & Post_Secedu_Support & -1.425 & .591 & 5.810 & 1 & .016 & .241 & .076 & .766 \\
\hline & General_Acadasupport & -.493 & 1.119 & .194 & 1 & .660 & .611 & .068 & 5.481 \\
\hline & Highschool_Grad & -12.360 & 19671.689 & .000 & 1 & .999 & .000 & .000 & . \\
\hline & Number_Psetting & -.337 & .532 & .402 & 1 & .526 & .714 & .252 & 2.025 \\
\hline & Length_Current_Psetting & -1.582 & .574 & 7.587 & 1 & .006 & .205 & .067 & .634 \\
\hline & Length_Previoussetting(1) & .088 & .566 & .024 & 1 & .877 & 1.092 & .360 & 3.311 \\
\hline & Total_Stay_inFC(1) & 1.159 & .926 & 1.564 & 1 & .211 & 3.186 & .518 & 19.577 \\
\hline & Number_Removals(1) & -.073 & .607 & .015 & 1 & .904 & .929 & .283 & 3.056 \\
\hline & Length_LastRemoval(1) & -1.467 & .864 & 2.885 & 1 & .089 & .231 & .042 & 1.253 \\
\hline & Constant & -46.863 & 48437.665 & .000 & 1 & .999 & .000 & & \\
\hline
\end{tabular}

a. Variable(s) entered on step 1: Placement_Type, Phyabuse, Sssexabuse, Neglect, Acad_Level,

Financial_Assistance,Post_Secedu_Support, General_Acadasupport, Highschool_Grad, Number_Psetting, Length_Current_Psetting, Length_Previoussetting, Total_Stay_Infc, Number_Removals, Length_Lastremoval.

Statistical results of the hierarchical binary logistic regression addressed the second hypothesis by determining the effect of Placement Type, Removal Reasons, Placement Stability, Academic Attainment and High School Grad on Adjudicated Delinquent when controlling for race, age and sex of the child. Based on the Nagelkerke R2 analysis the model including all the predictors explained $38.3 \%$ of the variance on the dependent variable, Adjudicated Delinquent. Although Model A was statistically significant, the explanatory power of the model was small (17.3\%). The second model was significantly improved by an additional $21 \%$. In other words, model B, which included all the variables explained $38.3 \%$ of the variance of the outcome variable, Adjudicated Delinquent. was the strongest predictor of juvenile delinquency. Since Model A and Model B were statistically significant, with a moderate explanatory power, there is enough evidence to accept the alternative hypothesis: Placement Type, Removal Reasons, Placement Stability, Academic Attainment and High School Grad are associated to a higher likelihood of adjudicated delinquent when controlling for race, age and sex.

\subsection{Hypothesis 3}

To answer the third hypothesis (youth with lower level of academic attainment will have a higher likelihood of becoming adjudicated delinquent, compared to youth who did have higher level of academic attainment, and this relationship is stronger for youth in non-kinship care compared to kinship care) a binary logistic regression was performed. The dependent variable, Adjudicated Delinquent was regressed on a set of independent variables. The sample size was $n=402$. Examining the model-fit statistics presented in Table 8, we see that the model was statistically significant when it was compared to the constant-only model $\left(\chi^{2}=46.346, p<.000\right)$, indicating that at least one of the involvement variables had a significant effect on the higher likelihood of Adjudicated Delinquent. 
The Hosmer and Leme show Test result revealed the model was a good fitting model, as $\mathrm{p}>.05(\mathrm{p}=.334)$. The involvement model correctly classified $92.3 \%$ of the cases. The Nagelkerke pseudo R2 indicated that the model with involvement items accounted for $38.3 \%$ of the total variance of the dependent variable, Adjudicated Delinquent (See Table 8).

Table 8:Hosmer and Lemeshow Test

\begin{tabular}{llll}
\hline Step & Chi-square & df & Sig. \\
\hline 1 & 9.098 & 8 & .334 \\
\hline
\end{tabular}

Turning now to the unstandardized logistic regression coefficients and their corresponding standard errors, Wald statistics, p-values, and odds ratios presented in Table 9, indicated that we should accept the Ho4: Youth lower level of academic attainment will have a higher likelihood of adjudicated delinquent, compared to youth who did have higher level of academic attainment, and this relationship is stronger for youth in non-kinship care compared to kinship care. Two variables made a statistically significant contribution to the model. The variables that were statistically significant at $\mathrm{p}=.05$ were, Financial_Assistance (presence of financial assistance) and Post_Secedu_Support (presence of postsecondary education support) as shown in Table 9. It is important to remember that predicted probability is of membership for "Yes", Adjudicated Delinquent.

Table 9: Variables in the Equation

\begin{tabular}{|c|c|c|c|c|c|c|c|c|c|}
\hline & \multirow[b]{2}{*}{ B } & \multirow[b]{2}{*}{ S.E. } & \multirow[b]{2}{*}{ Wald } & \multirow[b]{2}{*}{ df } & \multirow[b]{2}{*}{ Sig. } & \multirow[b]{2}{*}{$\operatorname{Exp}(B)$} & \multicolumn{2}{|c|}{$\begin{array}{l}\text { 95\% C.I.for } \\
\text { EXP(B) }\end{array}$} \\
\hline & & & & & & & & Lower & Upper \\
\hline Step & Sex & 1.156 & .580 & 3.968 & 1 & .046 & 3.178 & 1.019 & 9.911 \\
\hline $1^{\mathrm{a}}$ & Amiakn & 19.463 & 40193.077 & .000 & 1 & 1.000 & 283691847.333 & .000 & 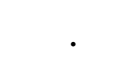 \\
\hline & Asian( & 18.023 & 27031.868 & .000 & 1 & .999 & 67165727.381 & .000 & \\
\hline & Blkafram & 1.965 & 1.364 & 2.076 & 1 & .150 & 7.135 & .493 & 103.346 \\
\hline & White & 1.357 & 1.332 & 1.037 & 1 & .308 & 883 & .285 & 52.832 \\
\hline & Hispanic & 827 & .622 & 1.764 & 1 & .184 & 2.286 & .675 & 7.743 \\
\hline & Age & 195 & .232 & .704 & 1 & .401 & 1.215 & .771 & 1.914 \\
\hline & Placement_Type & -1.104 & .673 & 2.690 & 1 & .101 & .332 & .089 & 1.240 \\
\hline & Phyabuse & 622 & .520 & 1.431 & 1 & 232 & 1.862 & .672 & 5.159 \\
\hline & Sexabuse & 1.091 & .709 & 2.367 & 1 & .124 & 2.978 & .742 & 11.961 \\
\hline & Neglect & 1.323 & .774 & 2.924 & 1 & .087 & 3.754 & .824 & 17.103 \\
\hline & Acad_Level & 16.796 & 19671.689 & . 000 & 1 & .999 & 19695203.319 & .000 & . \\
\hline & Financial_Assistance & -2.709 & .942 & 8.263 & 1 & .004 & .067 & .011 & .422 \\
\hline & Post_Secedu_Support & -1.425 & .591 & 5.810 & 1 & .016 & 241 & .076 & .766 \\
\hline & General_Acadasupport & -.493 & 1.119 & .194 & 1 & .660 & .611 & .068 & 5.481 \\
\hline & Highschool_Grad & $\begin{array}{c}- \\
12.360\end{array}$ & 19671.689 & .000 & 1 & .999 & .000 & .000 & . \\
\hline & Number_Psetting & -.337 & .532 & 402 & 1 & .526 & .714 & .252 & 2.025 \\
\hline & Length_Current_Psetting & -1.582 & .574 & 7.587 & 1 & .006 & .205 & .067 & 634 \\
\hline & Length_Previoussetting(1) & 088 & .566 & .024 & 1 & .877 & 1.092 & .360 & 3.311 \\
\hline & Total_Stay_inFC(1) & 1.159 & 926 & 1.564 & 1 & .211 & 3.186 & .518 & 19.577 \\
\hline & Number_Removals(1) & -.073 & 607 & 015 & 1 & .904 & .929 & .283 & 3.056 \\
\hline & Length_LastRemoval(1) & -1.467 & .864 & 2.885 & 1 & .089 & 231 & .042 & 1.253 \\
\hline & Constant & $\begin{array}{c}- \\
46.863\end{array}$ & 48437.665 & .000 & 1 & .999 & .000 & & \\
\hline
\end{tabular}

a. Variable(s) entered on step 1: Placement_Type, Phyabuse, Sssexabuse, Neglect, Acad_Level, Financial_Assistance, Post_Secedu_Support, General_Acadasupport, Highschool_Grad, Number_Psetting, Length_Current_Psetting, Length_Previoussetting, Total_Stay_Infc, Number_Removals, Length_Lastremoval. 
The variable Financial_Assistance (presence of financial assistance) was statistically significant and had a negative effect on the probability for the youth becoming adjudicated delinquent $(B=-2.709, p<.004)$. Statistical indices indicated that a one-level increase in this variable financial assistance (presence of academic financial assistance), is associated with 2.709 decrease in the logit of Adjudicated Delinquent. In other words, for each unit of increase in the independent variable financial assistance, there is a 27.09 times greater likelihood for the child to be Adjudicated Delinquent. The $\operatorname{Exp}(B)$ for this variable, Financial_Assistance was ,067, which indicated that when controlling for the effects of the other involvement items, each level increase in the juveniles' the presence of academic financial assistance decreased the odds of becoming adjudicated delinquent by $40.1 \%(100 *[.067=40.1 \%)$. Taken together, these results suggest that engagement in academic financial assistance (financial assistance) was a statistically significant predictor of juvenile delinquency at $\mathrm{p}<.000$ level of significance.

The variable, Post_Secedu_Support (presence of post-secondary education support) yielded a B of -1.425, S.E. $=.591$, Wald $=5.81, \mathrm{P}<.016$ and the $\operatorname{Exp}(\mathrm{B})$ was .241 . Statistical indices indicated that a one unit increase in this variable, Post_Secedu_Support is associated with 14. 25 decrease in the logit of delinquent behavior. That tells us that all else equal, the model predicts that the odds of the child becoming Adjudicated Delinquent decreased $70.6 \%(100 *[.241+$ $1]=70.6 \%$ ) for each unit increase in this variable, Post_Secedu_Support (presence of post-secondary education support) and it was statistically significant at $\mathrm{p}<.016$ level of significance. This variable, Post_Secedu_Support made a strong contribution to the model and is a statistically predictor of juvenile delinquency.

The variable, Placement Type did not have a statistically significant, effect $(B=.555, p<.343)$, indicating that this variable, Placement Type was not a predictor of Adjudicated Delinquent. Although only two variables in the model were statistically significant, the chi-square significance level of the model was less than 0.05 which calls for acceptance of the study hypothesis that the logistic regression model explains the variations in the likelihood of the occurrence of the dependent variable, Adjudicated Delinquent. After considering all the statistical results for the third hypothesis we must accept the study alternative hypothesis.

\subsection{Conclusion}

The present study examined the effect of the characteristics of the foster care children, which included, age, sex, and race on the likelihood of them becoming adjudicated delinquent. When a hierarchical linear regression was conducted to test the first study hypothesis the controlled variables age and sex of the child were found to be significant predictors of foster care children becoming adjudicated delinquent. The variable Placement Type was the indicator with the highest structure coefficient predicting juvenile delinquency. Results indicated that Placement Type and Adjudicated Delinquent did have a statistically significant relationship and the Cramer's Phi results showed a moderate effect (Phi/Cramer =.2.2, df (1).

The first alternative hypothesis was that Placement Type, Removal reasons, Academic Attainment and High School Grad are associated with a higher likelihood of adjudicated delinquent when controlling for race, age and gender.

As previously stated, Texas foster children placed with kinship caregivers and engaged academic attainment experience more positive outcomes.

The findings support the use of kinship care and engagement in academic attainment as statistical results indicated a negative effect of these variables and juvenile delinquency. In which kinship care settings provide stability and positive outcomes for children. Stability is essential for children, especially during their early formative years. Developmental psychologists stress that children experiencing stability and having the opportunity to develop secure attachments promote confidence and trust in others (Fairneau, 2016). Short lengths of stay away from the parents and minimal placement disruptions allow for children to feel a sense of security.

Children in kinship care placements had lower rates of placement disruption than children in Non-Kinship care. The majority of children in kinship care experienced a longer length of stay while in care as compared to children in NonKinship. Stability is a positive factor for kinship care placements and is consistent with the findings of Koh (2010), which indicated that once children are placed in kinship care settings, they are more likely to remain in these settings. Factors influencing this study's findings could be related to family dynamics, payment issues, or attributes of the child. Families' emotional ties and philosophical beliefs might encourage extended family members to provide on-going support to parents. The child could be allowed to return home with extended family providing in-kind support as needed. Another factor might be payment differentials in Texas for Kinship and Non-Kinship care placements. As stated previously, kinship caregivers do not receive subsidies for care unless they meet licensure criteria for licensed foster care placements. 
Moreover, there were some other relevant findings between the variables. Examination of the relationship between sex of the foster child, was a statistically significant predictor of placement stability at $\mathrm{p}=.004$ level of significance. Findings revealed that males comprised the majority $(n=221,55.0 \%)$ of the sample and children in non-kinship placement was the majority $(n=314,78.1 \%)$. Kinship care was more likely to be utilized for females than Non-Kinship care. These findings were supported by, McMillen, Zima, Scott, Auslander, Munson, Ollie, and Spitznagel (2005), which suggested that being male is associated with externalizing problems and lower levels of placement stability (Maschi, \& Bradley, 2008).

Nevertheless, McMillen et al. (2005), in a study of the prevalence of emotional and behavioral problems of adolescents in out-of-home placement, found that males and females did not differ in the frequency in placement stability.

\subsection{Implication for Practice}

Child welfare professionals often want to know what types of placements and services to focus on to improve positive outcomes for foster children. Child welfare reform has focused on encouraging placement with a child's kin over nonrelated foster care providers for several reasons. The first is that the belief that a placement with a relative may promote a sense of connection between foster care children and their family of origin. In addition, the foster relatives may be more likely to be invested in the child's future because they are family.The second is the shortage of non-related foster care providers and the difficulty in recruiting providers, in part due to increasing pressure for providers to adopt the children in their care. Recruiting family for a specific child is often easier and requires child welfare to provide less training and resources.

Assessing whether kinship care is linked with more positive outcomes is crucial in supporting or challenging the assertion that when possible, kinship placements should be considered over Non-Kinship placements. Statistical results further revealed a statistically significant relationship between removal reasons of sexual abuse, physical abuse, and neglect and adjudicated delinquent. The study used a hierarchical binary logistic regression to assess the effect of sexual abuse, physical abuse, and neglect on adjudicated delinquent, for those youth placed in non-kinship care, compared to youth placed in kinship care.

A study conducted by Koh (2010) examined the relationship between a child's placement type in foster care to removal reasons and delinquent behavior and found that those sexually abused with lower levels of behavioral problems were likely to be in kinship placement. Even if kinship placements promote more positive identity formation, the opportunity to live with kin may be negated by the child's sexual abuse history. There are several pathways through which child victims of abuse become delinquent and/or criminal. A child's final placement after the dissolution of a dependency petition filed with the Court is one possible link.

Thus, the findings presented underscore the importance of going beyond the fundamental relationship between placement type and children's wellbeing. Doing so will help us to identify factors like social support that mitigate the child's placement type adverse effect on child's positive outcome. The findings also contribute to theory concerning the relationship between social stress, social support, and individuals' outcomes.

This study adds an additional layer of knowledge to our current understanding regarding which stressors are mitigated by individuals' access to various types of social support regardless of the placement type. Such insight provides a foundation for future work exploring the association between childhood social stressors, social support accessibility, and children's behavioral outcomes.

\section{References}

Bell, W., \& Garner, J. (1996). What is kincare? Journal of Gerontological Social Work, 25(1/2),11-20.

Belanger, S.A. (2002). The advisability of kinship foster placements: A comparison ofadaptive behaviorsand psychopathology of children in traditional and kinship foster care. Dissertation Abstracts International, 62(12), 5993B. (UMI No. 3037209).

Berrick, J.D., Barth, R.P., \& Needell, B. (1994). A comparison of kinship foster homes and foster family homes: Implications for kinship foster care as family preservation. Children and Youth Services Review, 16, 34-5

Courtney, M.E., Dworsky, A., Ruth, G., Havlicek, J., Perez, A., \& Keller, T. (2007). Midwest evaluation of the adult functioning of former foster youth: outcomes at Age 21. Chicago: Chapin Hall Center for Children

Conway, T., \& Hutson, R. Q. (2007). Is kinship care good for kids? Report for the Center for Law and Social Policy. Retrieved on November, 2018 from http://www.clasp.org/admin/site/ publications/files/0347.pdf.

Denby, R. W. (2010). Kinship liaisons: A peer-to-peer approach to supporting kinship caregivers. Children and Youth Services Review, 33, 217-225.

Dworsky, A., Napolitano, L., \& Courtney, M., (2013). Homelessness during the transition from foster care to adulthood. American Journal of Public Health, 103(2), S31823. 
Ehrle, J., \& Green, R. (2002). Kin and non-kin foster care - findings from a national survey. Children and Youth Services Review, 24, 15-35.

Evans, L. (2014). Academic achievement of students in foster care: Impeded or improved? Psychology in the Schools, 41(5), $527-535$

Fairneau, H. (2016). An ecological approach to understanding delinquency of youthsin foster care. Deviant Behavior, 37(2), 139-150.

Foster, E. M., Hillemeier, M. M., \& Bai, Y. (2011). Explaining the disparity in placement

instability among African-American and white children in child welfare: A

Blinder-Oaxaca decomposition. Children and Youth Services Review, 33(1), 118-

125. http://doi.org/10.1016/j.childyouth.2010.08.021.

Freese, J. \& Long, J. S. (2006). Regression models for categorical dependent variables using Stata. College Station, TX: Stata Press.

Hegar, R. L., \& Rosenthal, J. A. (2009). Kinship care and sibling placement: Child behavior, family relationships, and school outcomes. Children and Youth Services Review, 31, 670-679.

Hegar, R., \&Scannapieco, M. (1999). Kinship foster care: Policy, practice, and research. New York, NY: Oxford University Press.

Hill, K. (2012). The prevalence of youth with disabilities among older youth in out-of-home placement: An analysis of state administrative data. Child Welfare, 91(4), 61-84.

Keller, T. E., Wetherbee, K., LeProhn, N. S., Payne, V., Sim, K., \& Lamont, E. R. (2001). Competencies and problem behaviors of children in family foster care: Variations by Kinship Placement status and Race/Ethnicity. Children and Youth Services Review, 23, 915-940.

Koh, E. (2010). Permanency outcomes of children in kinship and non-kinship foster care: Testing the external validity of kinship effects. Children and Youth Services Review, 32, 389-398.

Jenkins, M. H. (2002). Quality of care study of 76 kinship and 105 non-kinship foster children. Dissertation Abstracts International, 63(04), 1557.

Lenth, R. V. (2016). Java Applets for Power and Sample Size[Computer software]. Retrieved November 12, 2016, from: http://www.stat.uiowa.edu/ rlenth/Power

Luke, D. A. (2004). Multilevel Modeling: Quantitative Applications in the Social Sciences. Thousand Oaks, CA: SAge Publications, Inc.

Maschi, T., \& Bradley, C. (2008). Exploring the moderating influence of delinquent peers on the link between trauma, anger and violence among male youth: Implications for social work practice. Child Adolescent Social Work Journal, 25, 125-138. doi:10.1007/s10560-008-0116-2

McMillen, J. C, Zima, B. T., Scott, L. D., Auslander, W. F., Munson, M. R., Ollie, M. T., \&

SpitznAgel, E. L. (2005). Prevalence of psychiatric disorders among older youths in the foster care system. Journal of the of Child and Adolescent Psychiatry, 44, 88-95

Melkman, E., Refaeli, T., \&Benbenishty, R. (2016). An empirical test of a model of academic expectations among youth in residential care. Children and Youth Services Review, 67(1), 133- 141.

National Data Archive on Child Abuse and Neglect (NDACAN) (2015). Adoption and Foster Care Analysisand Reporting System (AFCARS) [Data file, user guide, and code book].National Resource Center on Youth Development, Children's Bureau (July 2016).

National Youth Transition Database (NYTD) (2016). Services File User's Guide. NDACANDataset \#207, FY 2011-2015. Cornell University. Ithaca, NY.

Rosenthal, J. (2012). Statistics and Data Interpretation for Social Work.

New York, N. Y.: SpringPublishing Company Rubin \& Babbie (2016). The practice of social research. Boston, MA: Cengage Learning

Shore, N., Sim, K. E., Prohn, N. S. L., \& Keller, T. (2002). Foster parent and teacher assessments of youth in Kinship and Non-Kinship foster care placements: Are behaviors perceived differentlyacross settings? Children and Youth Services Review, 24(1/2), 109-134.

Tabachnick, B. G., \&Fidell, L. S. (2007). Logistic regression using multivariatestatistics. Boston, MA: Pearson Education.

Testa, M. F. (2013). Systems of kinship care: Enduring challenges and emerging opportunities, Journal of Family Social Work, 16(5), 349-363.

Vanschoonlandt, F., Vanderfaeillie, J., Holen, F. V., De Maeyer, S., \&Andries, C. (2012). Kinship and non-kinship foster care: Differences in contact with parents and foster child's mental health problems. Children and Youth Services Review, 34(8), 1533-1539. doi: https://doi.org/10.1016/j.childyouth.2012.04.010

Vogt, W.P. (2005). Dictionary of statistics and methodology. Thousand Oaks, CA: SAge.

Zinn, A. (2012) Kinship foster family type and placement discharge outcomes. Children and Youth Services Review, 34, 602. 614. 